\title{
Rapid denture fabrication for institutionalized patients
}

\author{
Confecção rápida de prótese total para pacientes \\ institucionalizados
}

\begin{abstract}
Purpose: Edentulism is a common condition among the elderly population. However, it is difficult for elderly subjects who are institutionalized, hospitalized, or bedridden to visit dental offices for the repair or replacement of broken dentures. This paper describes a fast technique with minimum clinical sessions to fabricate a new maxillary denture.

Case description: An institutionalized 78-year-old man with an extremely damage broken maxillary denture complained about repairing his denture. With the impossibility of repairing, the technique described was proposed so as to offer a treatment that would maximize the comfort of the patient. The maxilla-mandibular relationship was done at the first clinical session, after fabricating the maxillary resin baseplate in mouth, by fixing the old complete mandibular denture with the maxillary wax plane. At the second clinical session, the esthetics and function of artificial teeth was checked and final impression was made to the denture installation at next session.

Conclusion: The reduced number of clinical sessions is a convenient option for clinicians to provide a more comfortable treatment for institutionalized or bedridden patients. This technique is also particularly useful when a replacement denture is urgently required, allowing its installation within few hours.
\end{abstract}

Key words: Institutionalized; elderly; denture

\section{Resumo}

Objetivo: $O$ edentulismo é uma condição comum dentre a população idosa. Entretanto, quando estes indivíduos encontram-se institucionalizados, hospitalizados ou acamados, consultar um cirurgião-dentista para reparo ou substituição de próteses totais pode ser uma situação difícil. Neste caso, é relatada uma técnica mais rápida para confecção de uma prótese total superior em um número mínimo de sessões clínicas.

Descrição do caso: Indivíduo institucionalizado de 78 anos de idade, apresentando uma prótese extremamente danificada após deixá-la cair sobre o chão, queixava de necessidade de reparo na mesma. Na impossibilidade de reparo, foi proposta esta técnica descrita para oferecer um tratamento com maior conforto para o paciente. $O$ relacionamento maxilomandibular foi feito na primeira sessão clínica, após confeccionar a base de prova diretamente em boca, fixando a própria prótese inferior do paciente com o plano de cera. Na segunda sessão clínica, a prova estética e funcional é feita e a moldagem final realizada para instalação da prótese na sessão seguinte.

Conclusão: $O$ número reduzido de sessões clínicas é uma opção conveniente para os clínicos e gera um tratamento mais confortável para indivíduos institucionalizados ou acamados. Esta técnica também pode ser útil para substituição de prótese total em caráter de urgência, onde a prótese pode ser instalada no mesmo dia ou no dia seguinte.

Palavras-chave: Institutionalização; idosos; prótese total
Plinio Mendes Senna a

Bruno Salles Sotto-Maior ${ }^{a}$

Joáo Paulo da Silva-Neto a

Alfonso Sanchez-Ayala ${ }^{a}$

Altair Antoninha Del Bel Cury a

a Department of Prosthodontics and Periodontology, Piracicaba Dental School, State University of Campinas, Piracibaba, SP, Brazil

\author{
Correspondence: \\ Altair A. Del Bel Cury \\ Piracicaba Dental School \\ State University of Campinas \\ Departament of Prosthodontics and Periodontology \\ Piracicaba, SP - Brazil \\ 13414-903 \\ E-mail: altcury@fop.unicamp.br
}

Received: July 29, 2011

Accepted: September 21, 2011

Conflict of Interest Statement: The authors state that there are no financial and personal conflicts of interest that could have inappropriately influenced their work.

Copyright: (C) 2011 Senna et al.; licensee EDIPUCRS. This is an Open Access article distributed under the terms of the Creative Commons AttributionNoncommercial-No Derivative Works 3.0 Unported License. 


\section{Introduction}

Edentulism is a widespread condition among elderly subjects, often causing personal embarrassment and leading to avoidance of social activities due to functional and psychological issues caused by a lack of dentures (1). The fracture of dentures is a common problem that affects up to $15 \%$ of the institutionalized elderly (2), many of whom can be bedridden or hospitalized. Institutionalized patients usually receive only emergency care since they often lack ready access to the dental clinics; many cannot be transported outside a long-term facility to receive regular dental treatment (3). Because of the management difficulties associated with these issues, it is common to repair broken dentures (4). However, depending upon the degree of damage, it may be difficult to obtain satisfactory results in terms of accurate fit or aesthetics, and a new denture is often needed. Nevertheless, the manufacturing of a complete denture is a time-consuming procedure, and institutionalized fragile patients generally cannot tolerate a large number of clinical sessions.

Given these challenges, a simple and fast technique for manufacturing new dentures for institutionalized patients is greatly needed. The dentures must be manufactured within the fewest possible clinical sessions without compromising the prosthesis quality, such as correct base extension, adaptation, proper occlusion and satisfactory aesthetics. Fewer clinical sessions are more tolerable for the patient and also minimize the inconveniences of mobility when the dentist has to go to the institution or the patient to be brought to the dental office several times.

In the present case report, we describe a rapid technique for manufacturing a new maxillary denture with no need of initial plaster cast models, thus completing the new denture treatment after approximately $8 \mathrm{~h}$ of total working time.

\section{Case description}

A nursing home facility requested the dental services provided by the dental school for an edentulous 78-yearold male patient, who had broken his maxillary denture after it had fallen on the floor. At the institution, the clinical examination revealed extreme damage to the maxillary denture. The mandibular denture was in satisfactory condition without signs of tooth wear. The fast technique to produce new dentures was proposed in order to offer an adequate treatment capable to maximize the patient's comfort and minimize the mobility and time constraints to the dental team.

The preliminary maxillary impression was done with silicone (Speedex Putty and Speedex Light-body; Vigodent, Rio de Janeiro, RJ, Brazil) using a stock tray for edentulous maxillary arch and the double impression technique. Special attention was given to record the impression of the buccal muscles while taking both impressions in order to minimize any overextension of the mold. Next, the posterior excess of the silicone impression was cut out (Fig. 1A), and petroleum jelly was applied to the palatal mucosa to minimize the patient's discomfort during the relining procedure.

The impression was relined with autopolymerizing polymethyl methacrylate (PMMA) resin (Jet; Classico, São Paulo, SP, Brazil). The tray was removed after a few seconds and the excess resin was cut out (Fig. 1B), while the mouth was rinsed to remove any residual monomer from palate. The tray was removed and replaced repeatedly until the final polymerization, so as to avoid burning the mucosa by the heat of the polymerization reaction.

Upon completion of the resin polymerization, the resin coverage was checked (Fig. 1C). Perforations of the resin layer were filled by addition of a small amount of resin with a brush followed by replacement of the tray in the mouth. The resin baseplate was then removed from the impression, finished to the proper extension by checking in mouth, and a wax rim was manufactured. After the labial support was adjusted and the occlusal vertical dimension was achieved, the reference lines were marked to guide the artificial teeth selection in terms of shape, size and color (the old broken denture also helped the team to select the right teeth model).

The existing complete mandibular denture was fixed with the maxillary wax plane in centric relation using zinc oxide and eugenol paste (Pasta Lysanda; Lysanda Produtos Odontológicos Ltda., São Paulo, SP, Brazil). The maxillary wax plane and the patient's mandibular denture were transferred with a facial bow to a semi-adjustable articulator (Fig. 1D), and fixed with a laboratory putty silicone (Zetalabor; Zhermack, Rodine, Italy). This completed the first session.

In the laboratory, the artificial teeth were assembled in occlusion with the old mandibular denture (Fig. 2). At the second clinical appointment, functional, phonetic and aesthetic checking of the mounted teeth on the maxillary baseplate was performed. After the patient's approval, the posterior palatal seal was relined with compound (Kerr; Kerr Corp, Orange, CA, USA) (Fig. 3A) and a final impression was done with zinc oxide eugenol impression paste in occlusion (Fig. 3B). The patient was instructed to bite lightly until the paste completely polymerized, avoiding a compressive impression of the denture-bearing mucosa.

The laboratory procedures were performed following standard steps using the technique of silicone mask and microwave polymerization. The final impression was filled with hard plaster (Durone IV; Dentsply, Petrópolis, RJ, Brazil) before investment in the bottom half of a polyvinyl chloride flask (Mufla VIPI STG, VIPI; Pirassununga, SP, Brazil). The wax was finished, and a lab putty silicone layer (Zetalabor; Zhermack) was applied before the final investment of the model in the flask (5). After the stone had cured completely, the flask was irradiated for $2 \mathrm{~min}$ at $720 \mathrm{~W}$ and $80 \%$ power in a ordinary microwave oven to remove the wax. The final cleaning was done with aliphatic hydrocarbon cleanser (Remox, VIPI, Pirassununga, SP, Brazil). 

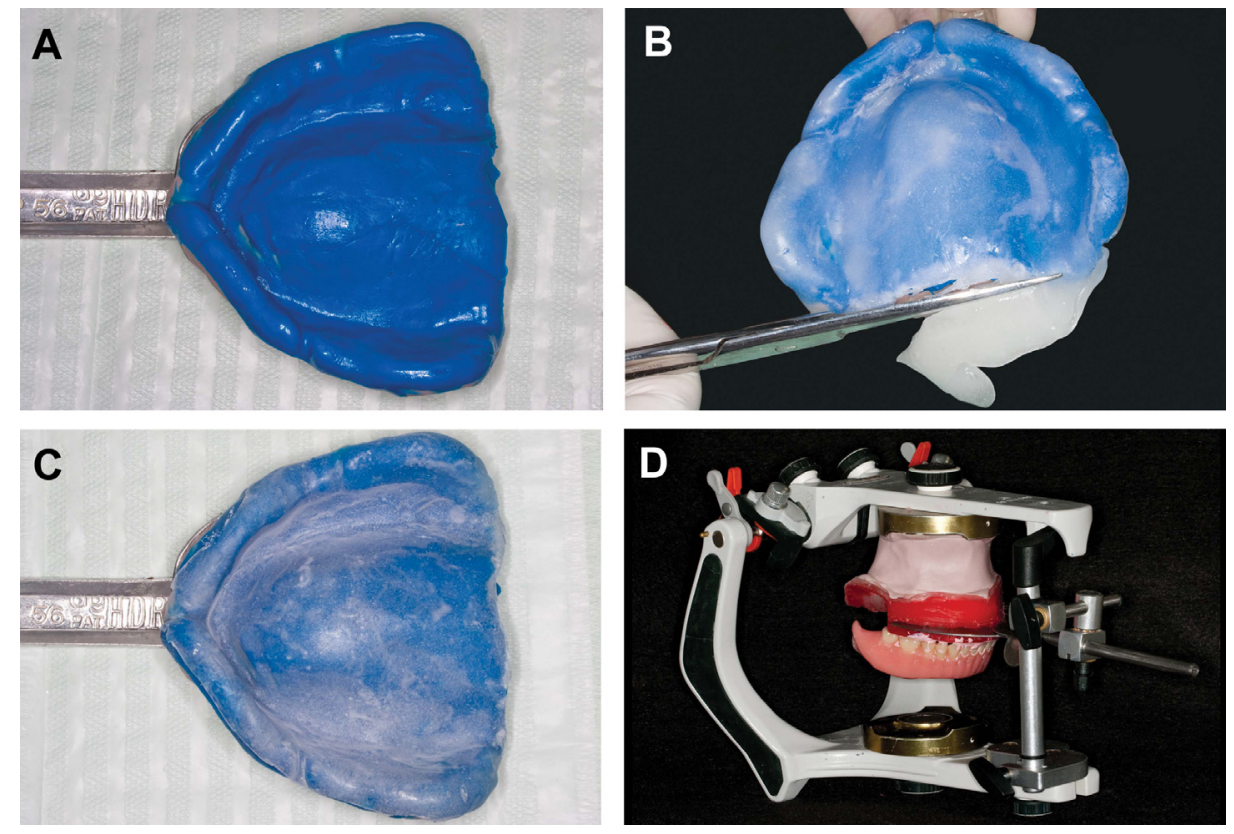

Fig. 1. First clinical session:

(A) Preliminary silicone impression;

(B) Excess resin from the PMMA relining procedure is removed just after tray settlement;

(C) Baseplate constructed with the PMMA resin relining procedure;

(D) Transfer to semi-adjustable articulator: the last procedure of the first clinical session.

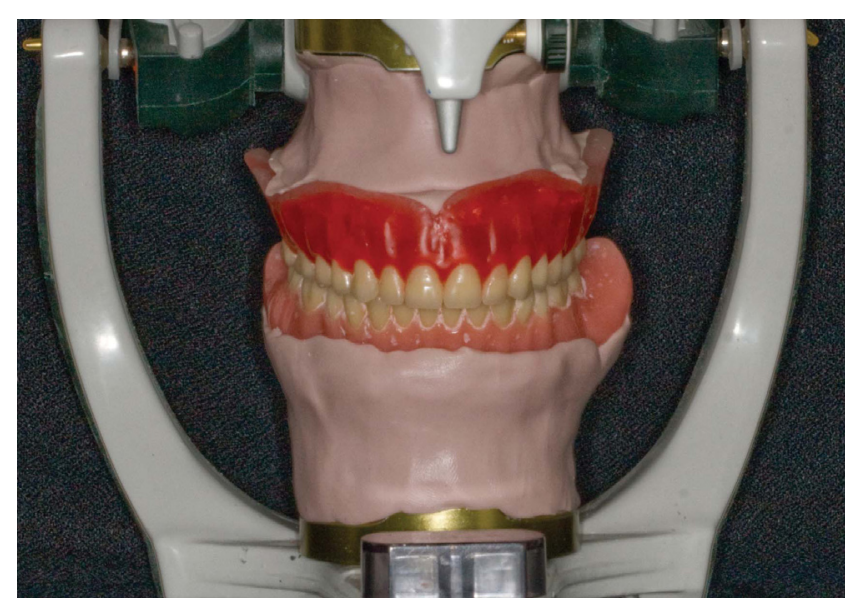

Fig. 2. In the lab, the new denture is fixed with lab putty silicone and the artificial teeth are mounted according to the occlusion with the old mandibular denture.

In order to improve the bond strength of the artificial teeth to the base resin of the denture, the prosthesis was further treated using low-speed burs and monomers before the insertion of the microwave-curing PMMA resin (OndaCryl; Classico, São Paulo, SP, Brazil) in the mould (6). After $30 \mathrm{~min}$ of the pressure stabilization in a hydraulic press, polymerization was carried out according to the manufacturer's protocol: 3, 4 and $3 \mathrm{~min}$ at $360 \mathrm{~W}, 0 \mathrm{~W}$ and $810 \mathrm{~W}$, respectively. The flask was cooled on the bench and opened; the denture was trimmed, finished and polished according to standard laboratorial procedures. Denture base and occlusal adjustments were done in the patient's mouth at the third clinical session (Fig. 4).
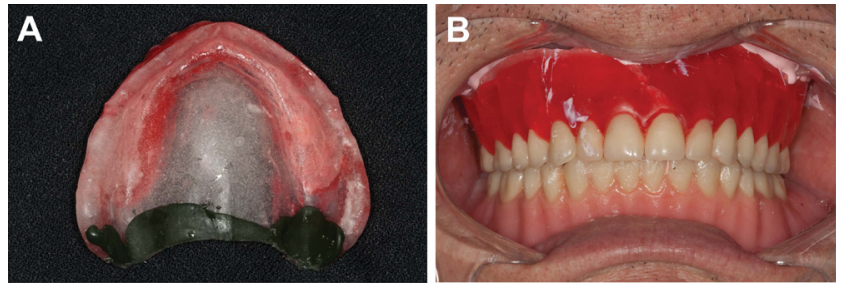

Fig. 3. Second clinical session. (A) Posterior palatal seal is refined with compound. (B) The final impression is taken with zinc oxide eugenol paste: the last procedure of the second clinical session.

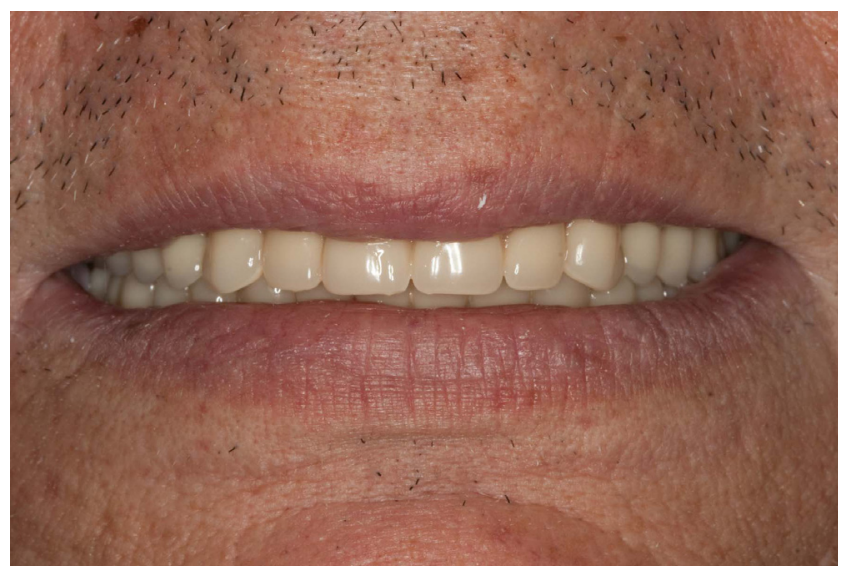

Fig. 4. Third clinical session: the new maxillary denture is installed. 


\section{Discussion}

This paper reports a novel technique for the rapid manufacturing of new maxillary dentures. It is indicated for institutionalized or hospitalized patients, patients with limited access to treatment facilities, or ordinary patients who have urgent need for replacement of a damaged denture. It is an efficient option to return the patient's denture and self-esteem in a few hours. After a total working time of approximately $8 \mathrm{~h}$, including laboratory procedures, a new denture was installed at the third clinical session, which could be performed even in the same in case of urgency.

Previously, a technique was described in which a new complete denture was fabricated in just one session (1). However, this technique utilizes autopolymerizing PMMA resin, a material that is prone to fracturing due to its poor mechanical properties, lower bond strength to artificial teeth, and higher residual monomer levels when compared to heat-polymerized PMMA resin $(7,8)$. Conversely, the present technique uses microwave polymerized resin, with satisfactory mechanical properties and fast and clean polymerization process (9), which are essential in urgent cases.

Since the elderly often have reduced manual dexterity due to neuromuscular diseases (10), the recurrence of denture fracture is high by dropping the dentures during the denture hygiene procedures or even during their insertion or removal from the mouth. This technique allows the fabrication of dentures of good technical quality and perhaps less prone to fracture over time due to the use of a heat-polymerizing resin. As it is also common the occurrence of losing dentures in this population (11), this technique also provides a rapid way for denture replacement.

The preliminary impression must be done concomitant to manipulation of the buccal muscles to minimize any baseplate overextension, which would require additional finishing time. Construction of the PMMA baseplate directly in the mouth, as well as the use of the patient's existing mandibular denture as the antagonist arch in the articulator, save the clinical and laboratorial time spent on manufacturing initial plaster cast models.

The use of facial bow allows any required adjustment of occlusal vertical dimension after the functional checking of the artificial teeth in mouth. Also, laboratory putty silicone was used for fixation of the baseplate and the complete mandibular denture. This material was chosen instead of dental stone because of its faster polymerization reaction, reducing the laboratory time required between the first and second clinical sessions.

Minor discomfort may be felt by the patient when the monomer is in contact with the mucosa during the PMMA relining procedure. The patient should rinse his mouth immediately after this procedure, which should eliminate any further effects. However, the patient should be asked about any sensitivity to the monomer, and this technique should be performed carefully in subjects with extremely retentive alveolar ridge.

Mandibular dentures can also be manufactured by using this technique; however, the use of the complete maxillary denture as antagonist can cause some emotional discomfort for the patient as the denture would be needed for the laboratorial procedures. In this case, the existing complete maxillary denture should be duplicated in dental stone in order to avoid depriving the patient of use of the maxillary denture for even a few hours. Thus, the mandibular wax plane with the occlusal record is transferred to the articulator. When both dentures need replacement, this technique will require four, rather than three, clinical sessions. Since elderly subjects usually cannot tolerate long sessions, the first clinical session must be divided into two parts, using one session to make the maxillary wax rim and the other to make the mandibular wax rim.

This technique is also particularly useful when a replacement denture is urgently required. In this case, the clinical session should be performed consecutively in the same day or at next day. The laboratory processing should be performed at dentist's own office, which only demands few specific equipments and some stock of artificial teeth; however, when it is not possible it will require a readiness commercial laboratory. The use of microwave energy to polymerize the PMMA base and silicon mask is also essential to reduce the time until denture installation.

This method is not intended to replace the conventional technique; rather, it is just an option to manufacture a new denture in fewer clinical sessions. The ability to manufacture dentures in a reduced number of clinical sessions provides a treatment option that is convenient for clinicians and is more comfortable to institutionalized or bedridden patients. Nevertheless, subjects presenting tissue lesions or pathologies should not be rehabilitated immediately; their oral health must be restored before any definitive treatment.

\footnotetext{
References 1. Becker CM, Swoope CC, Schwalm CA. Emergency dentures. J Prosthet Dent 1974;32: 514-19.

2. Vigild M. [Dental care for the elderly in nursing homes]. Tandlaegebladet 1986;90: 529-33.

3. Vigild M. [Oral health in institutionalized elderly]. Tandlaegebladet. 1990;94:169-94.

4. Goiato MC, Pesqueira AA, Vedovatto E, dos Santos DM, Gennari Filho H. Effect of different repair techniques on the accuracy of repositioning the fractured denture base. Gerodontology 2009;26:237-41.
} 
5. Zani D, Vieira DF. A comparative study of silicone as a separating medium for denture processing. J Prosthet Dent 1979;42:386-91.

6. Barbosa DB, Monteiro DR, Barao VA, Pero AC, Compagnoni MA. Effect of monomer treatment and polymerisation methods on the bond strength of resin teeth to denture base material. Gerodontology 2009;26:225-31.

7. Clancy JM, Boyer DB. Comparative bond strengths of light-cured, heat-cured, and autopolymerizing denture resins to denture teeth. J Prosthet Dent 1989;61:457-62.

8. Dogan A, Bek B, Cevik NN, Usanmaz A. The effect of preparation conditions of acrylic denture base materials on the level of residual monomer, mechanical properties and water absorption. J Dent 1995;23:313-8.

9. Del Bel Cury AA, Rached RN, Ganzarolli SM. Microwave-cured acrylic resins and siliconegypsum moulding technique. J Oral Rehabil $2001 ; 28: 433-8$.

10. Shay K. Denture hygiene: a review and update. J Contemp Dent Pract 2000;1:28-41.

11. Michaeli L, Davis DM, Foxton R. Denture loss: an 8-month study in a community dental setting. Gerodontology 2007;24:117-20. 